\title{
远震 $\mathbf{P}$ 波层析成像研究芫塘中央隆起带深部结构
}

邹长桥 ${ }^{(12)}$, 贺日政 ${ }^{(\mathbb{*} *}$, 高锐 ${ }^{(1)}$, 张智 ${ }^{(2)}$, 郑洪伟 ${ }^{(1)}$

(1) 中国地质科学院地质研究所, 北京 100037 ;

(2) 桂林理工大学地球科学学院, 桂林 541004

* 联系人, E-mail: herizheng@ @ cags.ac.cn

2012-01-31 收稿, 2012-03-16 接受

国家自然科学基金(40974060, 40774051, 40804017)、中国地质科学院地质研究所基本科研业务费专项资金(J0915)和国土资源部公益行业 基金(201011042, 201011044, 201011013)资助

摘要 利用在青藏高原㒸塘中部(TITAN-I 项目)部署的 54 套流动地震台站于 2008 年 9 月至 2010 年 11 月期间所记录的 506 个远震事件, 共9532个高质量的 P波初至走时数据运用 FMTT 方法进行层析成像反演, 获得了㒸塘中央隆起带下 $200 \mathrm{~km}$ 的深的地壳和上地幔三维 $\mathrm{P}$ 波速 度结构. 结果表明: 㒸塘中央隆起带的南北两侧块体的岩石圈速度结构明显不同. E-W 向剖

\section{关键词}

美塘中央隆起带 远震层析成像 断裂构造 面 $\left(33^{\circ}\right.$ 和 $\left.33.5^{\circ} \mathrm{N}\right)$ 显示, 其两侧的岩石圈结构尺度整体上存在明显差异, 南北芫塘地壳整体上 呈 E-W 向高速异常, 但北芫塘的高速异常已经延伸到岩石圈地幔, 且本研究区内北㒸塘盆地 的东部有明显的低速异常块体. 而沿 N-S 向的两条剖面 $\left(88.5^{\circ}\right.$ 和 $\left.89.5^{\circ} \mathrm{E}\right)$ 显示, 㒸塘中央隆起 带为一明显的边界构造断裂带.

青藏高原是由亚洲板块和印度板块在新生代时 期碰撞而形成 ${ }^{[1,2]}$, 在形成与演化过程中 ${ }^{[3,4]}$ 经历了复

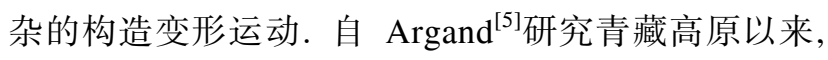
在国内外众多科学家长期不解努力和相互合作研究 下, 青藏高原研究已经取得突破性进展. 而对于青藏 高原形成机制 ${ }^{[6]}$ 尽管已有广泛的研究, 但仍然存在许 多不同的观点, 特别是有关它的深部结构和构造特 征. 随着研究的深人, 位于青藏高原腹地南北介于班 公怒江缝合带和金沙江缝合带之间的芫塘地体 ${ }^{[2]}$ (图 1)对解释青藏高原形成演化、高原隆升具有更重要的 科学价值.

属于特提斯构造域东段中部的㒸塘盆地内, 三 叠系和侏罗系分布较广, 是我国最大的中新生代海 相沉积盆地 ${ }^{[8,9]}$, 且岩层变形剧烈, 褶皱发育, 具有 良好的油气勘探前景 ${ }^{[10]}$. 而对于芫塘地体的演化模 式目前还存在两种不同的观点, 最主要是差塘中央 隆起的成因认识分歧所致.一种观点认为芫塘盆地 被中央隆起分隔, 但有着统一的基底 ${ }^{[9,11,12]}$. 而另一

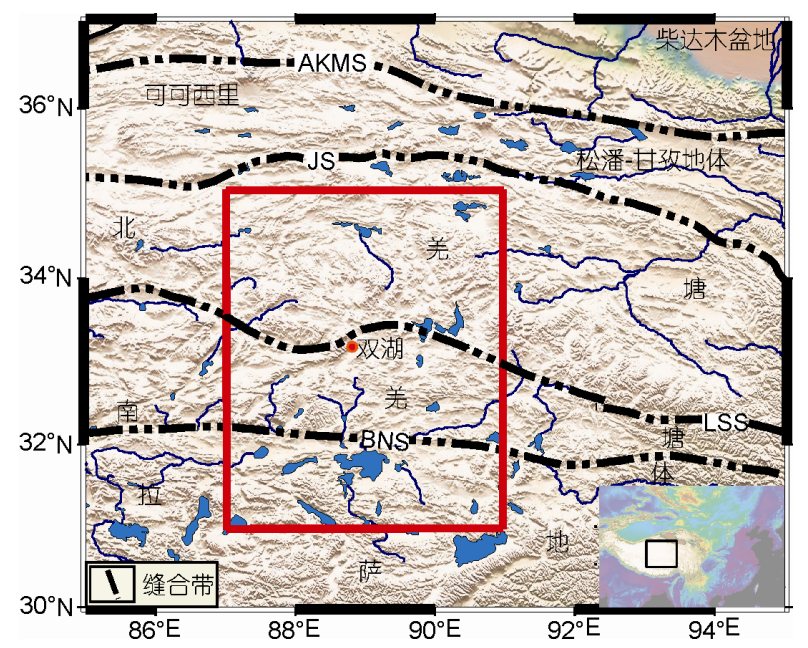

图 1 本研究区及邻区主要构造特征

红色方框为本文研究区. BNS, 班公-怒江缝合带; JS, 金沙江缝合 带; LSS, 龙木错-双湖缝合带; AKMS, 阿尼玛卿-昆仑-木孜塔格 缝合带. 中国及邻区大地构造图根据文献[7]修改

观点认为南北㒸塘分属于两个演化机制和整个岩石 圈尺度结构完全不同的构造单元 ${ }^{[13 \sim 17]}$. 而芫塘中央 
隆起带出露地层最全, 构造变形机制复杂, 是了解整 个盆地发育与演化的一个重要窗口, 其对沉积相带 的展布、盆地的后期构造变形等均起控制作用, 也是 研究印度板块与欧亚板块碰撞的关键部位 ${ }^{[18]}$.

截至目前, 在芫塘盆地及邻区开展了重力、磁 力、大地电磁测深和宽频带等地球物理调查研究工 作 ${ }^{[19 \sim 45]}$. 这些工作的开展, 主要是针对青藏高原多 地体间拼合过程中地球动力学深部结构特征以及芫 塘盆地基底构造研究, 从而使得我们对㒸塘中央隆 起带的深部结构有了初步认识.

大地电磁、宽频带地震及深地震测深研究结果显 示, 芫塘中央隆起带两侧深部结构特征存在明显差

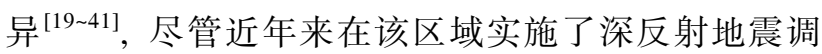
查研究 ${ }^{[42 ~ 45]}$, 但因其结构复杂, 难以取得清晰的深 部结构特征, 而宽频带流动地震观测能够在区域构 造尺度上给出较之上述方法相对清晰的证据.

在多方资助下, 中国地质科学院地质研究所在芫 塘盆地开展了宽频带地震观测研究工作(TITIAN-I), 布设了 54 套流动宽频带地震观测台站(图 2), 以便从 区域尺度上了解姜塘中央隆起带及其南北两侧盆地 深部结构特征. 本文利用该台网从 2008 年 9 月至 2010 年 11 月所记录到的远震 $\mathrm{P}$ 波走时数据和适应复

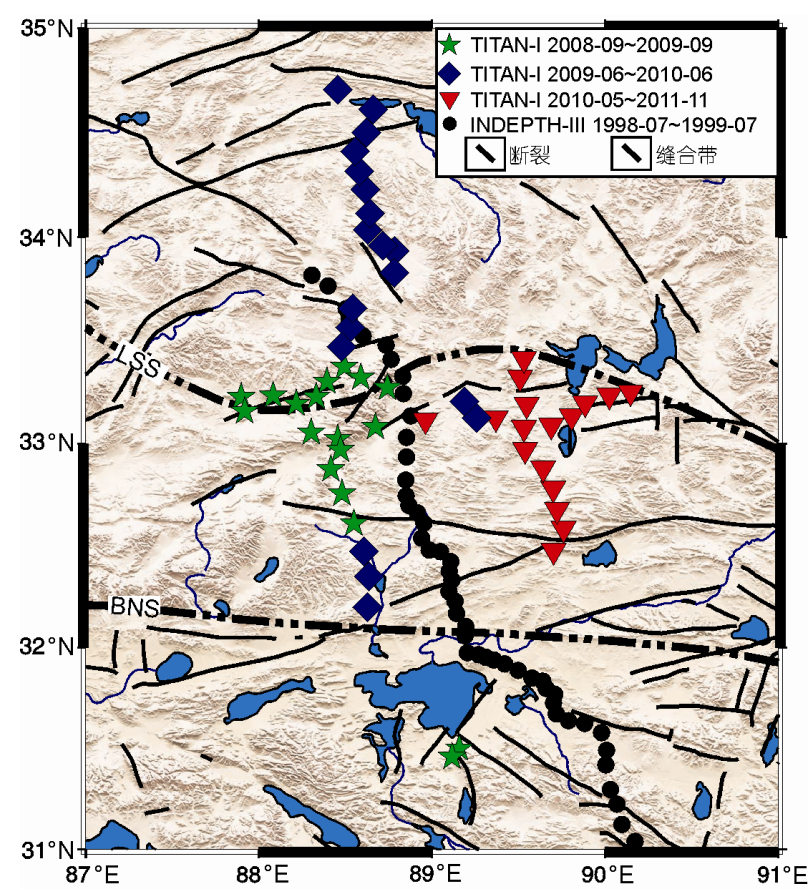

图 2 本文研究区内流动宽频带地震台站分布 图例同图 1
杂结构的层析成像算法 ${ }^{[46]}$, 研究芫塘中央隆起带深 部结构特征.

\section{1 构造背景}

从地形上看, 芫塘中央隆起夹于南北羌塘坳陷 之间(图 1), 时代较老的变质岩近东西向出露于美塘 地体中部的冈玛错、玛依岗日、查桑至西雅尔岗一线, 是芫塘地体内发育最全, 分布最广泛的海相沉积层 系 ${ }^{[9,47 ~ 50]}$, 且横亘于盆地中央的前侏罗系隆起带 ${ }^{[11]}$ 在过去的数十年里, 对于芫塘中央隆起的成因存在 不同的看法.一种观点认为芫塘中央隆起带是在伸 展环境下形成的，如王成善等人 ${ }^{[9,51]}$ 认为是晚古生代 末期的陆间裂谷作用后隆升的结果; Kapp 等人 ${ }^{[52,53]}$ 认为是金沙江洋向南俯冲到芫塘地体下部引起的隆 升和伸展剥离作用而形成的. 这样, 芫塘中央隆起带 将芫塘盆地分为南北羌塘盆地 ${ }^{[9,11]}$, 有着统一的基 底 ${ }^{[9,11,12]}$. 而另一种完全相反的观点则认为芫塘中央 隆起带为一古特提斯缝合带 ${ }^{[12,16,17]}$. 如李才等人 ${ }^{[54]}$ 认为是晚二叠世关闭时残留的混杂岩带, 芫塘中部 的冈玛日-桃形错的蓝片岩是晚古生代冈瓦纳大陆和 劳亚大陆间的古特提斯洋闭合的位置 ${ }^{[13 \sim 17,54,55]}$, 即古 特提斯缝合带. 榴辉岩和蓝片岩带内蓝闪石形成年 龄 ${ }^{[17,54]}$ 显示, 该缝合带的主碰撞时间为三叠世早期 (约 $220 \mathrm{Ma}$ ), 最终于三叠纪末形成. 羌塘中央隆起在 中泥盆世至早白严世经历了大陆裂离-大洋化-碰撞 闭合过程 ${ }^{[54]}$. 显然, 该缝合带 ${ }^{[13 ~ 17,54,55]}$ 把传统上的芫 塘地体 ${ }^{[3,4]}$ 分隔为两个演化机制和岩石圈尺度结构完 全不同的构造单元的南北芫塘地体 ${ }^{[7,16]}$. 这些分歧影 响了对㒸塘地体乃至整个青藏高原的形成和演化过 程的研究.

此外, 尽管羌塘地体(图 1)经历了新生代强烈的 火山活动 ${ }^{[56-59]}$ 和东西向伸展构造 ${ }^{[60 ~ 62]}$ 等后期改造, 但不论哪种观点, 记录着芫塘中央隆起带形成过程 的原始深部构造特征是否仍能完好地保留下来函需 回答, 进而深化㒸塘区域构造特征的认识.

因此, 本文利用流动的宽频带地震台网记录到 的地震波数据, 运用远震 $\mathrm{P}$ 波层析成像技术获取该区 的深部速度结构图像, 并结合其他地球物理证据, 认 识该区域的深部构造特征.

\section{2 数据和方法}

本文利用 TITAN-I 项目(图 2)在 2008 年 9 月至 
2010 年 11 月间所记录的远震事件(图 3). 这 54 套流 动地震台站采用的全是 CMG-3ESP_60s 的地震计和 REFTEK-130-1 数据采集器. 数据记录的采样率为 50 Hz. 流动台站的间距为 $10 \mathrm{~km}$ 左右, 并在芫塘中央隆 起带内对台站适当的加密处理(图 2). 在数据解编过 程中, 对台站位置参数经行了月平均处理, 同时也考 虑了 GPS 的高程与地震计之间的高差.

本文研究的这些远震事件 $\mathrm{Ms}$ 震级满足不小于 5.5 , 震中距在 $30^{\circ} \sim 90^{\circ}$ 之间 (这样尽量避免核幔边界 和下地幔中的复杂构造对地震波走时的影响), 地震 事件的震源参数源自美国地质调查局(USGS, http:// www.usgs.gov/), 且每个地震事件至少被 5 个台站接 受. 共挑选出 506 个地震事件的 9532 条远震 $\mathrm{P}$ 波到 时数据, 对原始数据进行去平均及 $0.5 \sim 1 \mathrm{~Hz}$ 的带通 滤波利用波形互相关技术拾取所有地震台站接收的 $\mathrm{P}$ 波到时，精度可以达到 0.1 0.2 s.

利用一维的 IASP91 地球模型 ${ }^{[63]}$, 可以得出 P 波 的理论走时 $\left(T^{c a l}\right)$ 并根据地球的椭圆率 ${ }^{[64]}$ 校正. 对于 第 $j$ 个地震事件被第 $i$ 个台站记录得到的远震走时残 差 $\left(\Delta t_{i j}\right)$ 可用下式表示为

$$
\Delta t_{i j}=T^{\mathrm{obs}}-T^{\mathrm{cal}},
$$

式中 $T^{\mathrm{obs}}$ 为观测值. 对于远震而言, 由于震源一侧远 离台站部分的射线路径基本相同, 只有靠近台站部

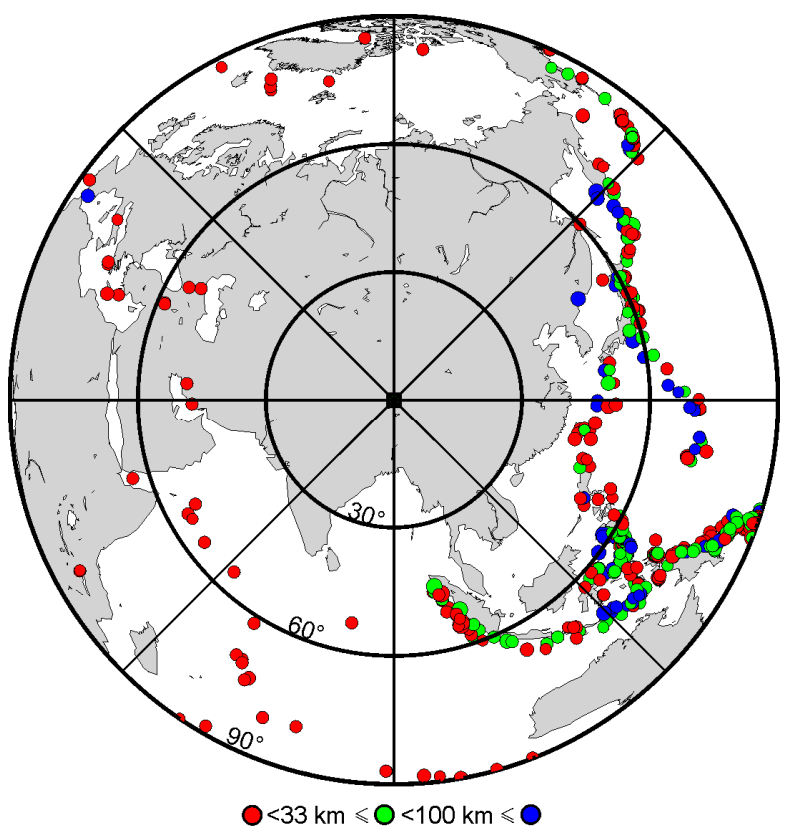

图 3 本文研究中远震事件震中分布 中间的小方块为本研究区
分其射线路径才有明显差别, 作为一级近似, 射线远 离台站部分对走时残差的贡献, 包括震源位置和发 震时刻的误差及脉冲初至位置的选择的影响, 对同 一地震是不随台站变化的. 为了降低震中错位、震源 时间以及研究区域外的速度异常影响, 因此, 通过式 (1)计算出第 $j$ 个地震事件的相对走时残差 $\left(\Delta r_{i j}\right)$ 如下:

$$
\Delta r_{i j}=\Delta t_{i j}-\frac{1}{n_{j}} \sum_{i}^{n_{j}} t_{i j},
$$

$n_{j}$ 表示台站记录的第 $j$ 个地震事件被记录到的地震台 站总数. $\Delta r_{i j}$ 就是用于远震层像成像的相对走时残差 资料. 对于同一台站记录到的所有远震的走时残差 求平均得到了远震走时的相对残差:

$$
\Delta r^{s}=\frac{1}{M} \sum_{k=1}^{M} r_{i j},
$$

其中 $M$ 表示该台站记录到的所有地震事件总数. $\Delta r^{s}$ 表示每个台站的平均相对走时残差.

为了适应羌塘盆地复杂的构造特征, 本文采用 球坐标下的 FMM(fast marching method)方法 ${ }^{[46,65 ~ 68]}$ 来进行射线追踪 ${ }^{[6870]}$. 该算法的核心思想是利用由 节点组成的窄带模拟波前曲面的演化, 再利用后差 分求取程函方程的弱解.

尽管青藏高原地壳有较强的横向不均匀性 ${ }^{[71 ~ 78],}$ 但是在本文研究中使用的相对走时残差幅值不超过 $2.0 \mathrm{~s}$. 在此基础上反演了地壳和上地幔的三维速度 结构中, 且并没有进行地壳校正. 一方面是因为青藏 高原区域没有合适的地壳模型可以利用, 另一方面 是因为此前的研究表明上地幔结构很大程度上不取 决于这一研究地区的地壳模型 ${ }^{[79,80]}$. 本文采用地壳 部分的初始参考速度模型参考了文献[37,81], 地壳 以下的深层速度结构由 IASP91 模型得到.

在模型空间内建立了 3-D 网格, 在横向上采用 $0.5^{\circ} \times 0.5^{\circ}$ 的网格格点, 垂向网格的间距是 $40 \mathrm{~km}$, 节 点间的速度值利用 B-样条插值获得. 本文采用了带 阻尼的 LSQR 算法 ${ }^{[22,83]}$ 进行反演计算. 在计算过程中, 我们对阻尼系数选取做了大量的实验, 选择了最佳 的阻尼系数为 10 (图 4). 图 5 是反演前后相对走时残 差分布的统计结果, 经过 10 次反演迭代后, 残差绝 大部分集中在-0.3 0.3 s 之内.

\section{3 结果}

本文检测板的输人模型是在参考模型的基础上 加一个正负相间分布的 $3 \%$ 的速度扰动并辅以 $1 \%$ 的 


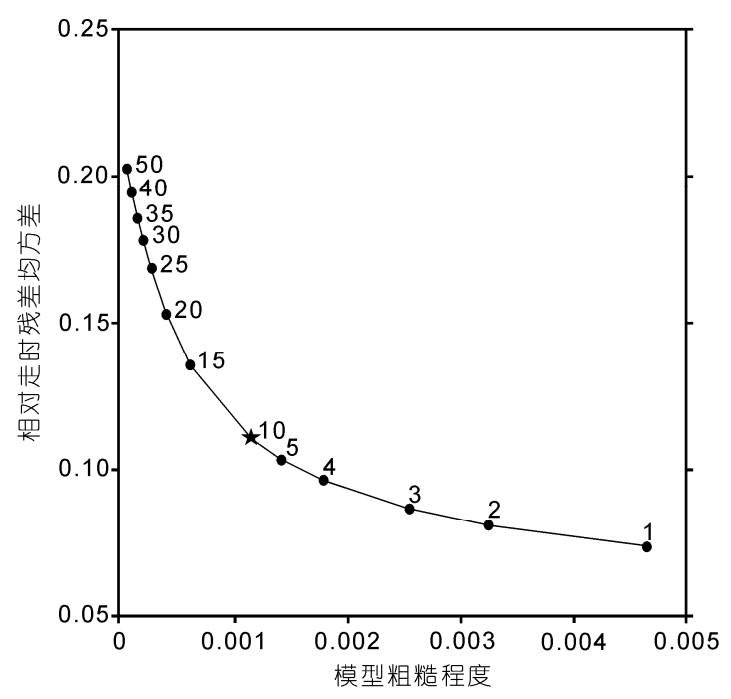

图 4 阻尼系数

星型为最佳阻尼系数

随机误差. 浅部研究区 (深度 $\leqslant 20 \mathrm{~km}$ )具有较低的分辨 率, 因为远震射线在地壳内部不能够很好地交叉, 这 种现象在远震层析成像研究中非常普遍. 尽管研究 区东的西太平洋海域地震事件相对更为集中, 但本 次研究中台站比较密集且分布比较集中, 因此台站

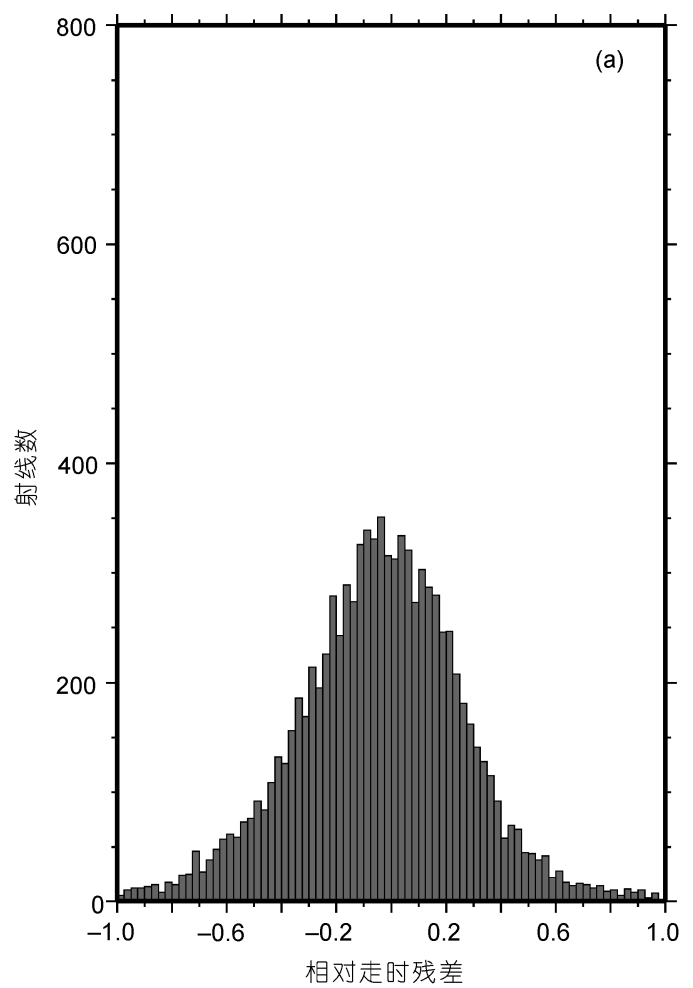

下方的地震射线在地壳和上地幔内部很好地交叉(图 6), 模型分辨率较好.

图 7 给出了不同深度上的棋盘格检测结果. 由于 本研究区内部署的地震台站较为密集, 显然在 200 $\mathrm{km}$ 以上大部分地区的分辨率较好, 所以该研究区内 的剖面速度扰动图像也是相当可靠的(图 8). 层析成 像结果(图 8)显示: 在芫塘盆地中上地壳部分的 $\mathrm{P}$ 波 速度异常呈近 N-S 向(图 8(a)), 而在下地壳到岩石圈 上地幔部分的 P 波速度异常形态(图 8(b) (d)) 与边界 断裂的特征 ${ }^{[34]}$ 较为相似. 根据垂向剖面的棋盘格检 测结果(图 9)和地震台站的分布(图 2), 在本研究台网 密集覆盖下的岩石圈结构异常特征较为可靠.

为了便于体现 $P$ 波速度异常的深度变化特征，依 据台站分布及大地构造特征，在芫塘中央隆起带的 南北两侧切了 $A A^{\prime}$ (沿 $33^{\circ} \mathrm{N}$, 如图 10(a)) 和 $B B^{\prime}$ (沿 $33.5^{\circ} \mathrm{N}$, 如图 $\left.10(\mathrm{~b})\right)$ 两条东西向剖面, 以及 $C C^{\prime}$ $\left(88.5^{\circ} \mathrm{E}, 32.1^{\circ} \mathrm{N} ; 88.5^{\circ} \mathrm{E}, 35^{\circ} \mathrm{N}\right.$, 如图 $\left.10(\mathrm{c})\right)$ 和 $D D^{\prime}($ 沿 $89.5^{\circ} \mathrm{E}, 32.1^{\circ} \mathrm{N} ; 89.5^{\circ} \mathrm{E}, 34.1^{\circ} \mathrm{N}$, 如图 $10(\mathrm{~d})$ )两条南北 向剖面, 这些剖面的垂向 $\mathrm{P}$ 波速度扰动如图 10 所示.

E-W 向的两个垂直剖面(图 10(a)和(b)中的 $A A^{\prime}$ 和 $B B^{\prime}$ 剖面)P 波速度扰动图像，清楚地显示中央隆起

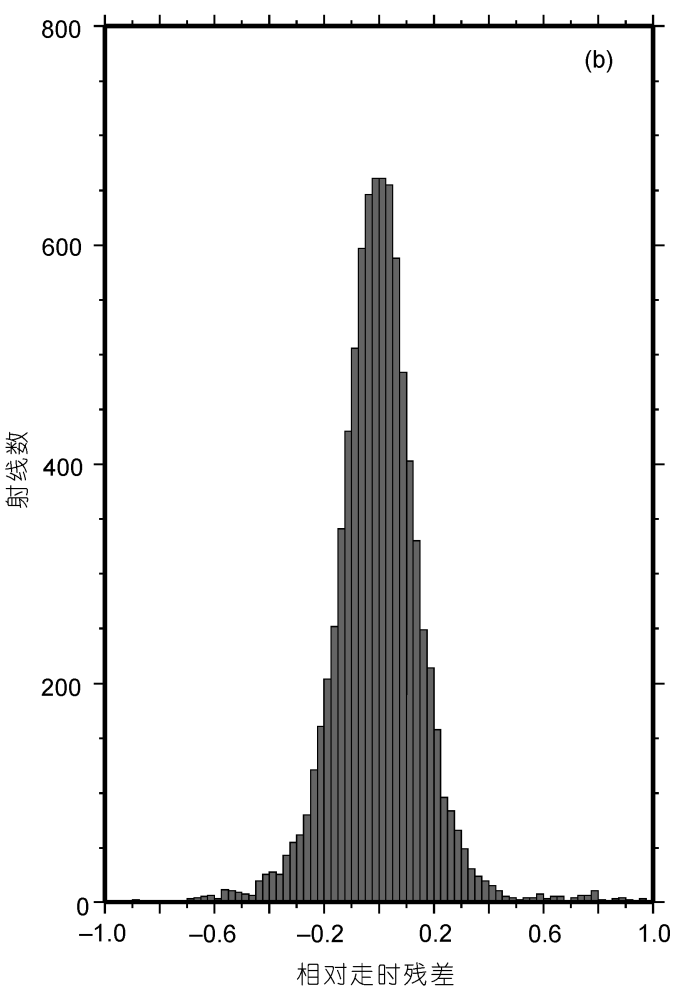

图 5 反演前(a)和反演后(b)相对走时残差分布 


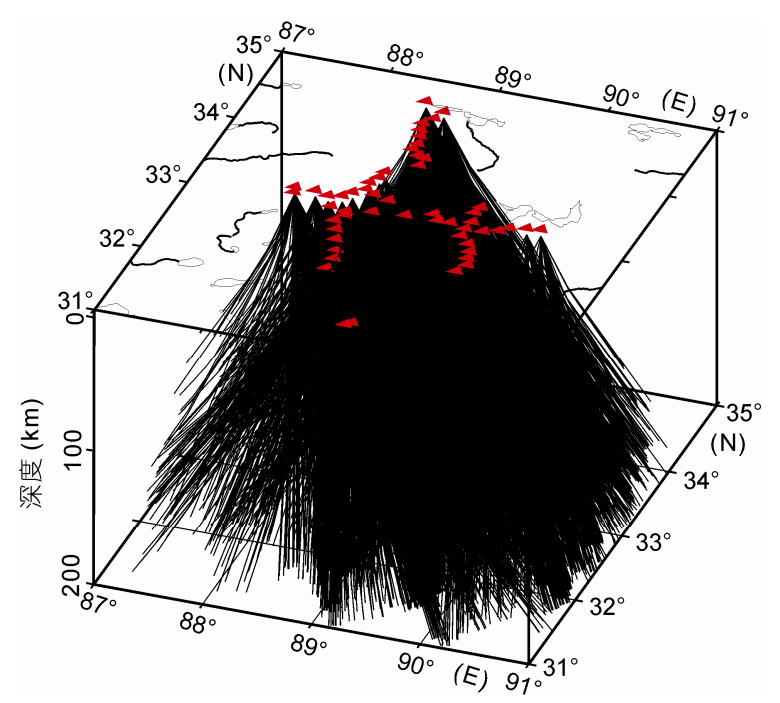

图 6 本研究区内的地震射线分布

带两侧岩石圈结构异常差异非常明显, 而南差塘盆 地的整个地壳相对于北芫塘盆地显示为高速异常体, 这些特征与其他地震层像成像结果相似 ${ }^{[35,37,41,81]}$.

S-N 向的两个垂直剖面(图 10(c)和(d)中的 $C C^{\prime}$ 和
$D D^{\prime}$ 剖面)P 波速度扰动剖面成像图像, 显示中央隆起 带为一明显的构造边界过渡带, 这也与其他地球物 理学研究成果 ${ }^{[19 \sim 41]}$ 相一致. 中央隆起区南部与北部 的上地壳结构也存在一定的差异, 这与横过芫塘地 体中央隆起区的深反射地震实验结果相一致 ${ }^{[44,45]}$. 南芫塘盆地中下地壳部分的自南往北高速异常逐渐 增厚并延伸到中央隆起带下方 $150 \mathrm{~km}$ 深处, 而岩石 圈上地幔部分的异常带呈 N-S 向越过中央隆起带并 延伸到北芫塘盆地; 而北芫塘盆地地壳部分表现为 低速异常, 这与地震学研究 ${ }^{[37,41]}$ 结果大体一致. 在芫 塘中央隆起带下方 60 80 km 处, 存在一构造边界带, 莫霍面可能存在错断 ${ }^{[45,84,85]}$. 由于本次研究中台站位 置的限制, 现今的结果还不足以刻画整个北芫塘地 壳的异常结构, 随着后续工作的开展, 整个㒸塘地体 的深部结构可以得到更好的呈现.

综上所述，根据本文及综合其他地球物理研究 成果显示, 芫塘中央隆起带确实为一重要的边界构 造带, 且其南北两侧盆地间的深部结构存在明显差 异 ${ }^{[19 \sim 41]}$.
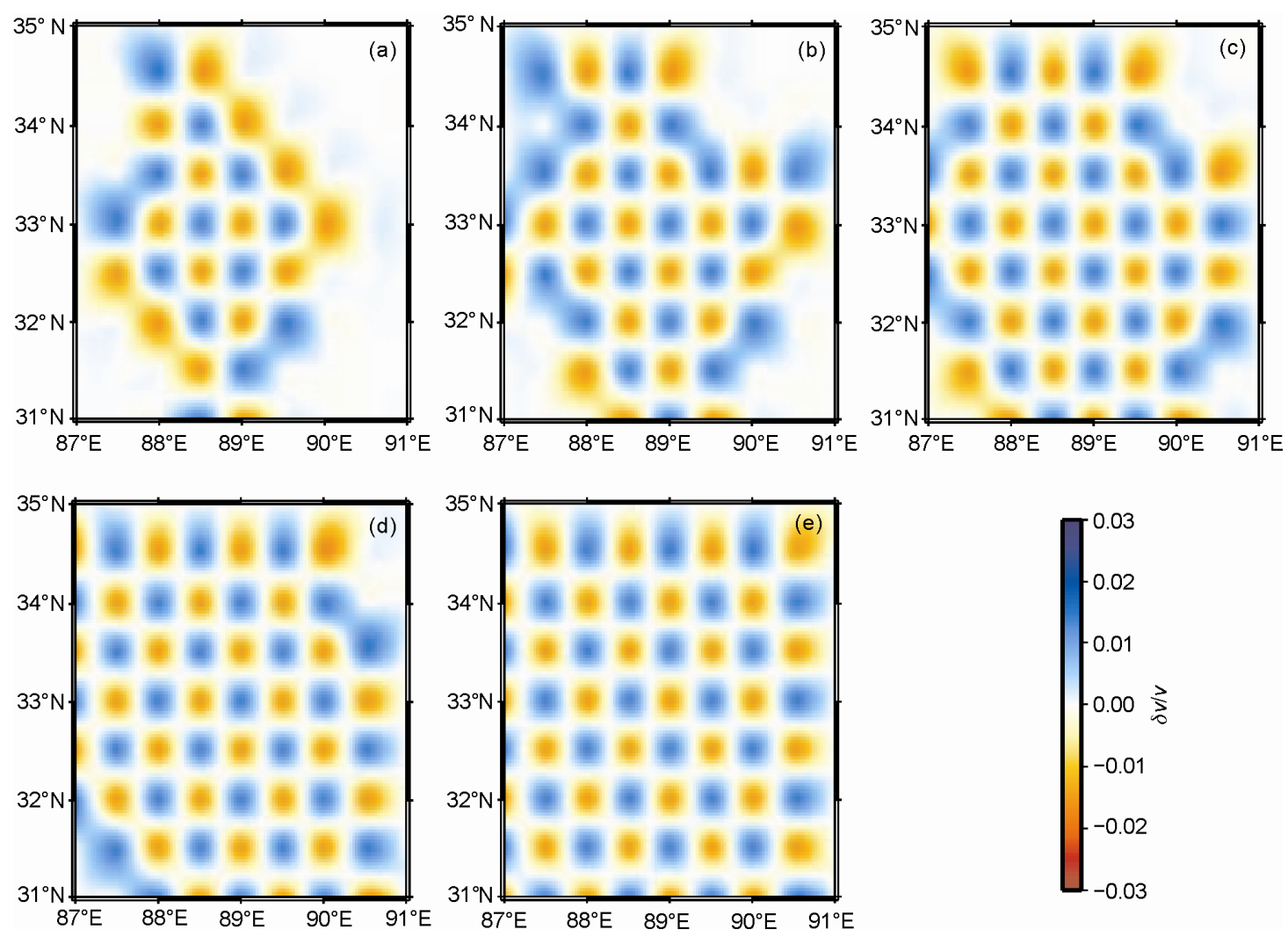

图 7 各个深度上的棋盘格检测结果

(a) $20 \mathrm{~km}$; (b) $60 \mathrm{~km}$; (c) $100 \mathrm{~km}$; (d) $140 \mathrm{~km}$; (e) $180 \mathrm{~km}$ 

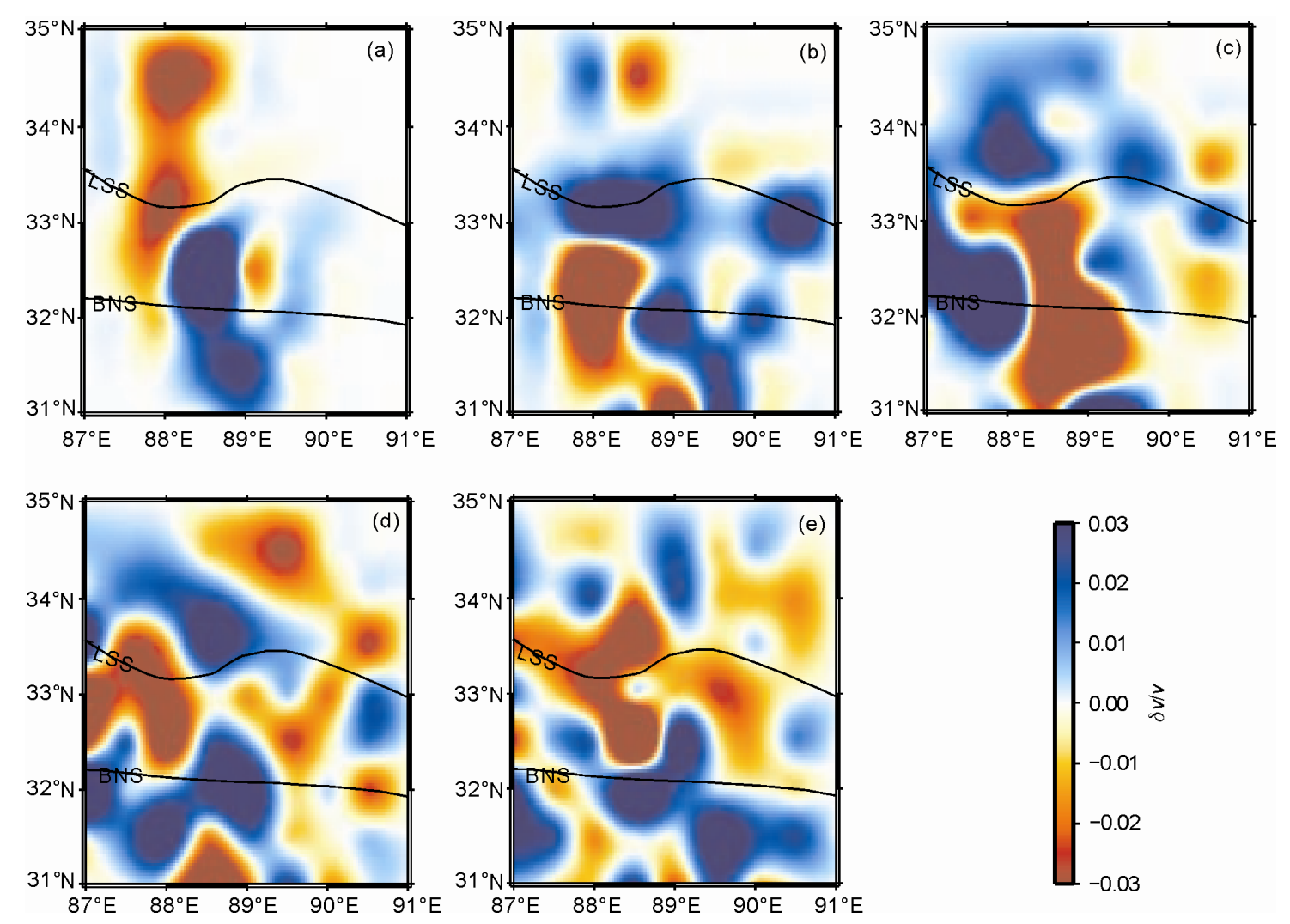

图 8 各个深度上的 $P$ 波速度扰动

(a) $20 \mathrm{~km}$; (b) $60 \mathrm{~km}$; (c) $100 \mathrm{~km}$; (d) $140 \mathrm{~km}$; (e) $180 \mathrm{~km}$. 图例同图 1
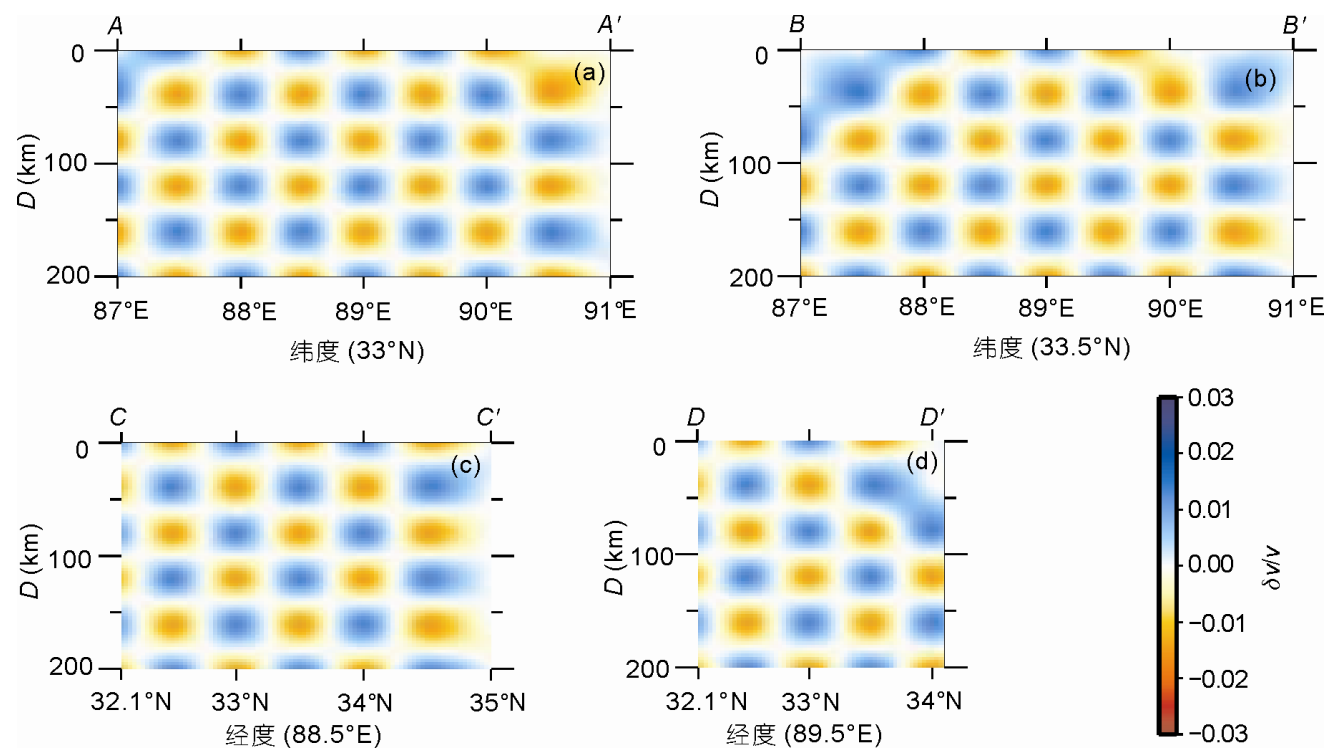

图 9 各个剖面的检测版测试结果

剖面位置见图 10 所示 


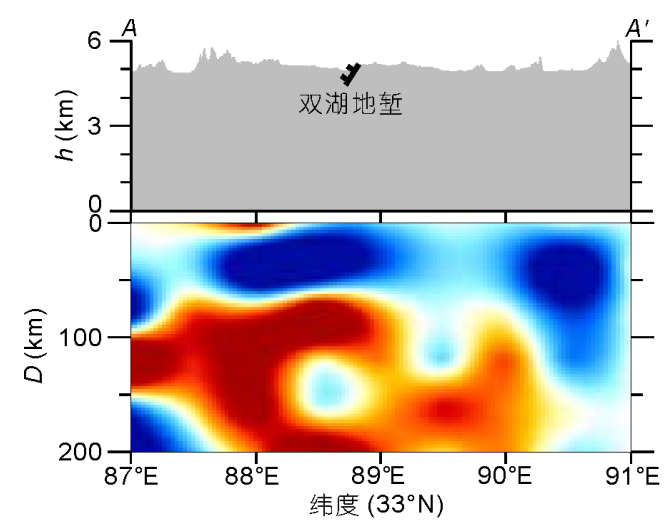

(a)

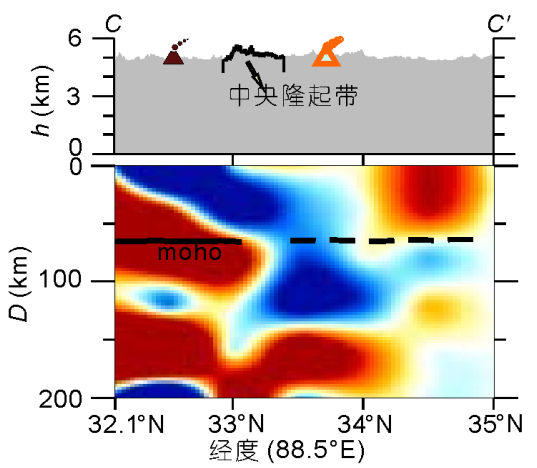

(c)

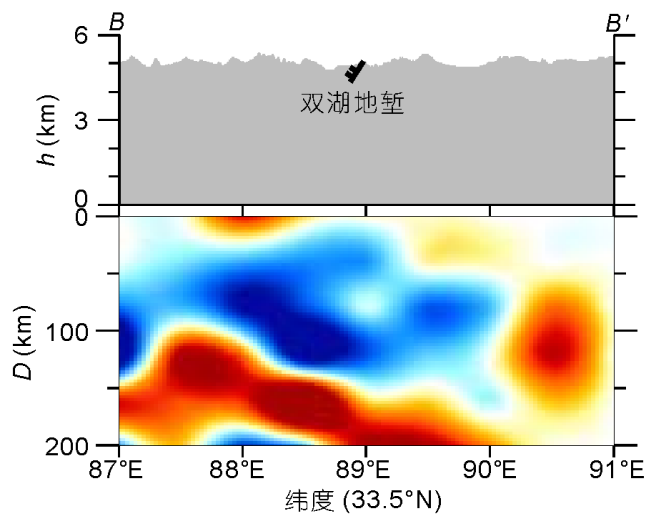

(b)

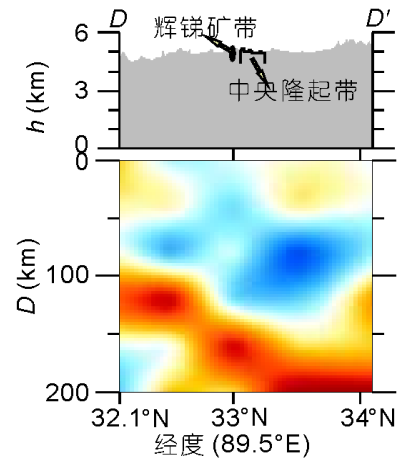

(d)

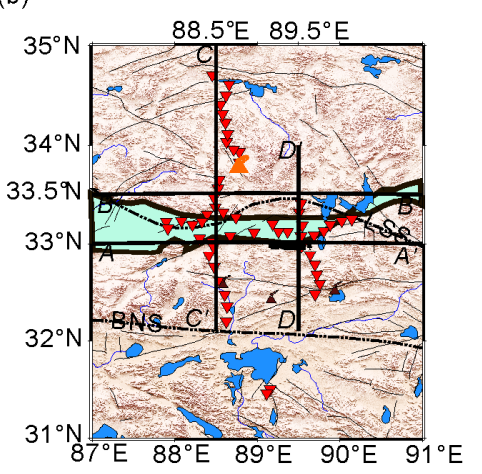

(e)

图 10 各个剖面 $P$ 波层析成像图以及剖面位置

图例同图 1 和 2. 剖面上方为地形图, (a) (d)表示为垂直剖面 P 波速度扰动, 纵向与横向比例约为 1:1; (e)中的阴影部分表示芫塘中央隆 起带的位置. 据文献[11]修改

\section{4 讨论}

芫塘盆地是我国最大的中新生代海相沉积盆 地 ${ }^{[9]}$, 芫塘中央隆起带将其分为南北两个盆地, 研究 芫塘中央隆起带的深部结构特征, 揭示其与南北两 侧盆地间的接触关系是认识姜塘盆地物质结构特征 以及芫塘油气资源远景的关键科学问题. 尽管芫塘 地体在青藏高原的形成和演化过程中遭到强烈的后 期改造, 但在收集并分析已有的地球物理资料基础 上认为㒸塘中央隆起带的深部结构与构造特征仍有 可能被完整地保留下来.

自从 20 世纪 80 年代以来, 在芫塘盆地实施了诸 多的地球物理调查研究 ${ }^{[19 \sim 45,81,84 \sim 89]}$, 这些研究工作 的开展认识了芫塘盆地基底构造的性质, 为更深人 了解芫塘中央隆起带的深部结构特征奠定了基础. 在这些调查研究沿着不同剖面获得的结果确大致相 同, 如沿新疆叶城至西藏狮泉河的大地电磁测深剖 面 ${ }^{[20]}$ 显示, 北芫塘底壳内只有一个低阻层, 而南美
塘壳内有两个低阻层; 孔祥儒等人 ${ }^{[21]}$ 应用青藏高原 吉隆 3 个湖综合地球物理剖面提供的重力、地磁和大 地电磁 ${ }^{[25}$ 对该区域密度、磁性结构和电性结构进行 综合性研究, 重力场和地磁异常研究表明, 地壳厚度 和地壳顶界面在芫塘地体内相差较大, 该研究区内 的电性结构表现出强烈的横向均匀性, 北芫塘与南 芫塘不同, 上地壳电阻率明显增大, 壳内高导层埋深 也增大; 而布置在青藏高原芫塘盆地内部的大地电 磁测深剖面 ${ }^{[22,29]}$ 详细分析芫塘盆地的深部电性结构, 研究显示芫塘盆地南北方向呈两坳夹一隆的电性特 征, 芫塘中央隆起带两侧的电性结构上具有明显的 电性差异. 这些电性特征同 INDEPTH-III 项目完成 德庆-龙尾错 (500 线) ${ }^{[34]}$ 和亚东-格尔木全球地学断面 沿青藏公路实施的大地电磁测深 ${ }^{[19]}$ 研究成果相一致. 另外, 高精度的航磁异常分析 ${ }^{[27]}$ 显示中央隆起带表 现为一强磁异常特征, 而布格重力异常匹配滤波分 析 ${ }^{[86]}$ 获得深部异常清楚显示芫塘中央隆起与其两侧 密度差异明显. 综合这些地球物理场特征研究结果 
表明羌塘中央隆起带为一重要的断裂构造带 ${ }^{[23,27,31]}$, 且其南北两侧的岩石圈结构存在明显差异.

正如上面所提到的地球物理场研究结果, 空间 分辨率相对较低, 相比较而言, 本文研究中获得了芫 塘中隆起带的 3-D 的地壳上地幔的 P 波速度模型. 如 图 10 显示的结果, 对比 $A A^{\prime}$ 和 $B B^{\prime}$ 剖面(图 10(a)和(b)) 成像图, 中央隆起带南北两侧的岩石圈速度结构明 显不同, 这也与远震层析成像图像 ${ }^{[37,41]}$ 结果一致. 而 三个湖-鲁谷综合剖面 ${ }^{[21]}$ 和 INDEPTH-III ${ }^{[26,30]}$ 的深地 震测深结果也显示, 㒸塘中央隆起两侧的地壳速度 明显不同.

根据 INDEPTH-III 剖面接收函数图像 ${ }^{[85]}$ 和深地 震测深研究 ${ }^{[26,84]}$, 及横过芫塘中央隆起带的深反射 地震实验 ${ }^{[45,85]}$, 在芫塘中央隆起带下莫霍面存在异 常, 与 $C C^{\prime}$ 剖面(图 10(c))成像图像显示的结果相一致. 尽管本文研究方法和数据资料的缺陷还不足以刻画 莫霍面深度的起伏变化, 但根据本文的层像成像结 果显示芫塘中央隆起带下为一明显的构造边界带, 结合上述研究成果 ${ }^{[26,45,84]}$ 确证莫霍面存在错断, 其错 断幅度需要进一步的研究.

另外, 芫塘中央隆起带下的北倾 $\mathrm{P}$ 波速度异常 (图 10(c)和(d))显示, 南羌塘地体的地壳部分整体已 经越过了芫塘中央隆起带, 并北向插人到北㒸塘地 体之下. 在芫塘中央隆起带下的这种地壳结构特征, 与深反射地震实验结果 ${ }^{[45,85}$ 较为相似. 同时, 本项研 究给出了较之 ${ }^{[45,85]}$ 清晰的羌塘中央隆起带下岩石圈 尺度上的整体结构轮廓. 目前, 越来越多的地表地 质、构造地质与地球化学证据 ${ }^{[7,13,16,17,54,55]}$ 表明, 芫塘 中央隆起带 ${ }^{[9,11,47 \sim 55]}$ 被认为是一个古特提斯洋于晚二 叠-早侏罗关闭后的古特提斯缝合带(又叫龙木错-双
湖缝合带). 如图 10(c)和(d)所示的清楚的 P 波速度异 常特征也较符合缝合带所特有的深部结构特征. 尽 管远震层析成像方法局限性约束了对地壳精细结构 的认识, 但结合深反射地震实验 ${ }^{[45,85]}$ 给出的反射地 壳结构特征, 推测这种 P 波速度异常特征(图 10(c) 和 (d)) 可能反映了龙木错-双湖缝合带 ${ }^{[7,13,16,17,54,55]}$ 形成 后所遗留的深部结构特征.

因此，芫塘中央隆起带两侧的南芫塘和北芫塘 分属于整个岩石圈尺度结构完全不同的两个构造单 元. 通过地球物理研究 ${ }^{[19 \sim 41,45]}$ 获得的芫塘中央隆起 的深部结构认识及其南北两侧的盆地间的构造关系, 有利于更好地认识南北芫塘盆地基底性质以及对姜 塘油气资源远景的准确评价.

\section{5 结论}

本文通过部署在西藏中部的 54 套宽频带流动地 震台站记录的 504 个远震事件, 共计 9532 个 $\mathrm{P}$ 波走 时数据, 对芫塘中央隆起带及周缘地区的层析成像 反演. 与前人研究结果相比, 我们的层析成像图像有 着更好的分辨率，对芫塘中央隆起带的深部结构提 供了新的资料. 本次工作的主要结论如下:

层析成像图像研究发现羌塘中央隆起带为一重 大边界构造断裂带, 其两侧的岩石圈结构存在明显 差异. 沿芫塘中央隆起带南北两侧的 E-W 向剖面 $\left(33^{\circ}\right.$ 和 $\left.33.5^{\circ} \mathrm{N}\right)$ 显示, 其两侧的岩石圈结构尺度整体 上存在明显差异, 南北㒸塘盆地地壳整体上呈高速 异常，但北芫塘的高速异常已经延伸到岩石圈地幔， 且本研究区内北芫塘盆地的东部有明显的低速异常 块体. 而沿 $\mathrm{N}-\mathrm{S}$ 向的两条剖面 $\left(88.5^{\circ}\right.$ 和 $\left.89.5^{\circ} \mathrm{E}\right)$ 显示, 芫塘中央隆起带为一明显的边界构造断裂带. 都是 GMT 软件包绘制而成.

\section{参考文献}

1 Dewey J F, Shackelton R M, Chang C, et al. The tectonic evolution of the Tibetan Plateau. Philos Trans R Soc A, 1988, 327: 379-413

2 Yin A, Harrison T M. Geologic evolution of the Himalayan-Tibetan orogen. Earth Planet Sci, 2000, 28: 211-280

3 常承法, 潘裕生, 郑锡澜. 青藏高原地质构造. 北京: 科学出版社, 1982

4 尹安. 喜马拉雅-青藏高原造山带地质演化一一显生宙亚洲大陆生长. 地球学报, 2001, 22: 193-230

5 Argand E. La Tectonique de L'Asie. Proc 13th Int Geol Congress, 1924, 7: 171-372 
6 高锐. 青藏高原岩石圈结构与地球动力学的 30 个为什么. 地质论评, 1997, 43: 460-464

7 任纪舜. 中国及邻区大地构造图. 北京: 地质出版社, 1997

8 鲁兵, 李永铁, 刘忠, 等. 青藏高原的盆地形成与分类. 石油学报, 2000, 21:21-26

9 王成善, 伊海生, 李勇, 等.西藏㒸塘盆地地质演化与油气远景评价. 北京: 地质出版社, 2001

10 赵政璋, 李永铁, 郭祖军, 等. 青藏高原油气勘探前景. 勘探家, 1997, 2: 14-16

11 黄继钧. 藏北芫塘盆地构造特征及演化. 中国区域地质, 2001, 20: 178-186

12 尹福光. 芫塘盆地中央隆起性质与成因. 大地构造与成矿, 2003, 27: 143-146

13 李才. 龙木错-双湖-澜沧江板块缝合带与石炭-二叠纪冈瓦纳北界. 长春地质学院学报, 1987, 17: 155-166

14 邓希光, 丁林, 刘小汉, 等. 藏北㒸塘中部冈玛日-桃形错蓝片岩的发现. 地质科学, 2000, 35: 227-232

15 邓希光, 丁林, 刘小汉, 等. 青藏高原芫塘中部蓝片岩的地球化学特征及其构造意义. 岩石学报, 2002, 18: 517-525

16 李才, 翟庆国, 董永胜, 等. 青藏高原羌塘中部榴辉岩的发现及其意义. 科学通报, 2006, 51: 70-74

17 李才, 翟庆国, 陈文, 等. 青藏高原芫塘中部榴辉岩 Ar-Ar 定年. 岩石学报, 2006, 22: 2843-2849

18 Gao R, Lu Z W, Li Q S, et al. Geophysical survey and geodynamic study of crust and upper mantle in the Qinghai-Tibet Plateau. Episodes, 2005, 28: 263-273

19 郭新峰, 张元丑, 程庆云, 等. 青藏高原亚东-格尔木地学断面岩石圈电性研究. 中国地质科学院院报, 1990, 21: 191-202

20 秦国卿, 陈九辉, 刘大建, 等. 昆仑山脉和喀喇昆仑山脉地区的地壳上地幔电性结构特征. 地球物理学报, 1994, 37: 193-199

21 孔祥儒, 王谦身, 熊绍柏. 青藏高原西部综合地球物理与岩石圈结构的研究. 中国科学 D 辑：地球科学, 1996, 26: 308-315

22 张胜业, 魏胜, 王家映, 等. 西藏羌塘盆. 地大地电磁测深研究. 地球科学, 1996, 21: 198-202

23 滕吉文, 张中杰, 万志超, 等. 芫塘盆地及周边地带地球物理场与油气深部构造背景初探. 地球物理学进展, 1996, 11: 12-27

Wittlinger G, Masson F, Poupinet G, et al. Seismic tomography of northern Tibet and Kunlun: Evidence for crustal blocks and mantle velocity contrasts. Earth Planet Sci Lett, 1996, 139: 263-279

马晓冰，孔祥儒，于暏. 青藏高原西部大地电磁测深结果. 科学通报, 1997, 42: 1185-1187

Zhao W, Mechie J, Brown L D, et al. Crustal structure of the central Tibet as derived from project INDEPTH wide-angle seismic data. Geophys J Int, 2001, 145: 486-498

27 刘池阳, 杨兴科, 魏永佩, 等. 藏北芫塘盆地西部查桑地区结构及结构特征. 地质论评, 2002, 48: 593-602

28 Tilmann F, Ni J, INDEPTH III Seismic Team. Seismic imaging of the down welling Indian lithosphere beneath central Tibet. Science, 2003, 300: 1424-1427

29 鲁兵, 徐可强, 刘池阳. 藏北㒸塘地区的地壳电性结构及其意义. 地学前缘, 2003, 10(Suppl): 153-159

30 Haines S, Klemperer S L, Brown L, et al. Crustal thickening processes in central Tibet: Implications of INDEPTH III seismic data. Tectonics, 2003, 22: 1-18

31 贺日政. 青藏高原近南北向裂谷的岩石圈结构及其动力学过程. 博士学位论文. 北京: 中国地质科学院, 2003

32 Wittlinger G, Vergne J, Tapponnier P, et al. Teleseismic imaging of subducting lithosphere and Moho offsets beneath western Tibet. Earth Planet Sci Lett, 2004, 221: 117-130

33 贺日政, 赵大鹏, 高锐, 等. 西昆仑造山带下岩石圈地幔速度结构. 地球物理学报, 2006, 49: 778-787

34 魏文博, 金胜, 叶高峰, 等. 藏北高原地壳及上地幔导电性结构——超宽频带大地电磁测深研究结果. 地球物理学报, 2006, 49: 1215-1225

35 He R Z, Zhao D, Zheng H, et al. Teleseismic P-wave tomography under the central Tibet Plateau. AGU-2006WPGM(Abstract), 2006. T12B-04

36 苑守成, 于国明，田黔宁。青藏高原芫塘盆地重磁剖面异常与基底构造特征. 地质通报, 2007, 26: 703-709

37 郑洪伟, 李廷栋, 高锐, 等. 印度板块岩石圈地幔向北俯冲到㒸塘地体之下的远震 $\mathrm{P}$ 波层析成像证据. 地球物理学报, 2007 , 50: $1418-1426$

38 王喜臣, 贾建秀, 徐宝慈. 㒸坳陷石油地质走廊剖面重磁异常处理模拟及地质解释. 吉林大学学报(地球科学版), 2008, 38: 685-691

39 Wang X C, Jia J X, Xu B C. Gravity and Magnetic modeling and geological explanation in Qiangtang basin geologic aisle. J Jilin University (Earth Sci Ed), 2008, 38: 685-691

40 田黔宁, 耿涛, 杨汇群, 等. 青藏高原西部重力异常剖面拟合及其地质解释. 地质通报, 2008, 27: 2108-2116

41 He R Z, Zhao D P, Gao R, et al. Tracing the Indian lithospheric mantle beneath central Tibetan Plateau using teleseismic tomography. Tectonophysics, 2010, 491: 230-243

42 方立敏, 鲁兵, 刘池阳, 等. 㒸塘盆地中部隆起的演化及其在油气勘探中的意义. 地质论评, 2002, 48: 279-283

43 Ross A R, Brown L D, Pananont P, et al. Deep reflection surveying in central Tibet: Lower-crustal layering and crustal flow. Geophys J Int, 2004, 156: 115-128

44 卢占武. 青藏高原芫塘盆地岩石圈结构及其对油气远景的影响. 博士学位论文. 北京: 中国地质科学院, 2006 
47 赵政璋, 李永铁, 叶和飞, 等. 青藏高原㒸塘盆地石油地质. 北京: 科学出版社, 2000. 19-34

48 赵政璋, 李永铁, 叶和飞, 等. 青藏高原大地构造特征及盆地演化. 北京: 科学出版社, 2000

49 赵政璋, 李永铁, 王岫岩, 等. 芫塘盆地南部海相侏罗系古油藏例析. 海相油气地质, 2002, 7: 34-36

50 王剑，谭富文，李亚林，等. 青藏高原重点沉积盆地油气资源潜力分析. 北京：地质出版社, 2004. 32-61

51 王成善, 胡承祖, 吴瑞忠, 等. 西藏北部查桑-茶布裂谷的发现及其地质意义. 成都地质学院学报, 1987, 14: 33-46

52 Kapp P, Yin A, Manning C E, et al. Blueschist-bearing metamorphic core complexes in Qiangtang block reveal deep crustal structure of northern Tibet. Geology, 2000, 28: 19-22

53 Kapp P, Yin A, Manning C E, et al. Tectonic evolution of the early Mesozoic blue schist bearing Qiangtang metamorphic belt, Central Tibet. Tectonics, 2003, 22: 1043-1069

54 李才, 程立人, 胡克, 等. 西藏龙木错-双湖古特提斯缝合带研究. 北京: 地质出版社, 1995

55 李才, 王天武, 杨德明, 等. 西藏㒸塘中央隆起区物质组成与构造演化. 长春科技大学学报, 2001, 31: 25-31

56 邓万明，郑锡澜，松本征夫. 青海可可西里地区新生代火山岩的岩石特征与时代. 岩石矿物学, 1996, 15: 289-298

57 Hacker B R, Gnos E, Ratschbacher L, et al. Hot and dry deep crustal xenoliths from Tibet. Science, 2000, 287: 2463-2466

58 Chung S L, Chu M F, Zhang Y Q, et al. Tibetan tectonic evolution inferred from spatial and temporal variations in post-collisional magmatism. Earth Sci Rev, 2005, 68: 173-196

59 罗照华, 莫宣学, 侯增谦，等. 青藏高原新生代形成演化的整合模型-来自火成岩的约束. 地学前缘, 2006, 13: 196-211

60 Yin A, Paul A K, Michael A M, et al. Significant late Neogene east-west extension in northern Tibet. Geology, 1999, 27: 787-790

61 Blisniuk P M, Hacker B R, Glodny J, et al. Normal faulting in central Tibet since at least 13.5 Myr ago. Nature, 2001, 412: 628-632

62 李亚林, 王成善, 伊海生, 等. 西藏北部双湖地堑构造与新生代伸展作用. 中国科学 D 辑: 地球科学, 2001, 31(增刊): 228-233

63 Kennett B L N, Engdahl E R. Traveltimes for global earthquake location and phase identification. Geophys J Int, 1991, 105: 429-465

64 Dziewonski A, Gilbert F. The effect of small aspherical perturbations on travel times and a re-examination of the corrections for ellipticity. Geophys J Int, 1976, 44: 7-17

65 Sethian J A. Numerical Methods for Propagating Front, in Variational Methods for Free Surface Interfaces. New York: Springer-Verlag, 1987

66 Sethian J A, Progoviciz A M. 3-D traveltime computation using the fast marching method. Geophysics, 1999, 64: 516-523

67 Popoviciz A M, Sethian J A. 3-D imaging using higher order fast marching traveltimes. Geophysics, 2002, 67: 604-609

68 Rawlinson N, Reading A M, Kennett B L N. Lithospheric structure of Tasmania from a novel form of telescismic tomography. J Geophys Res, 2006, 111: 322-330

69 郭彪，刘启元，陈九辉，等.川西龙门山及邻区地壳上地幔远震 P 波层析成像. 地球物理学报, 2009, 52: 346-355

70 张风雪, 李永华, 吴庆举, 等. FMTT 方法研究华北及邻区上地幔 P 波速度结构. 地球物理学报, 2011, 54: 1233-1242

71 Hirn A, Jiang M, Sapin M, et al. Seismic anisotropy as an indicator of mantle flow beneath the Himalayas and Tibet. Nature, 1995, 375: 571-574

72 Brown L, Zhao W, Nelson K, et al. Bright spots, structure, and magmatism in Southern Tibet from INDEPTH seismic reflection profiling. Science, 1996, 274: 1688-1690

73 Hirn A, Sapin M, Lépine J C, et al. Increase in melt fraction along a south-north traverse below the Tibetan Plateau: Evidence from seismology. Tectonophysics, 1997, 273: 17-30

74 Hirn A, Diaz J, Sapin M, et al. Variation of shearwave residuals and splitting parameters from array observations in southern Tibet. Pure Appl Geophys, 1998, 151: 407-431

75 Huang W, Ni J, Tilmann F, et al. Seismic polarization anisotropy beneath the central Tibetan Plateau. J Geophys Res, 2000, 105: 27979-27989

76 Rapine R, Tilmann F, West M, et al. Crustal structure of northern and southern Tibet from surface wave dispersion analysis. J Geophys Res, 2003, 108, doi: 10.1029/2001JB000445

77 Shapiro N M, Ritzwoller M H, Molnar P, et al. Thinning and flow of Tibetan crust constrained by seismic anisotropy. Science, 2004, 305: $233-236$

78 Zhang Z, Klemperer S L. West-east variation in crustal thickness in northern Lhasa block, central Tibet, from deep seismic sounding data J Geophys Res, 2005, 110: B09403

79 Li C, Hilst R, Toksoz M. Constraining spatial variations in P-wave velocity in the upper mantle beneath SE Asia. Phys Earth Planet Int, 2006, 154: 180-195

80 Lei J S, Zhao D. Teleseismic P-wave tomography and the upper mantle structure of the central Tien Shan orogenic belt. Phys Earth Planet Int, 2007, 162: 165-185 
81 郑洪伟. 青藏高原地壳上地幔三维速度结构及其地球动力学意义. 博士学位论文. 北京: 中国地质科学院, 2006

82 Paige C C, Saunders M A. LSQR: An algorithm for sparse linear equations and sparse least squares. ACM Trans Math Softw, 1982, 8: 43-71

83 Paige C C, Saunders M A. LSQR: An algorithm for sparse linear equations and least squares problems. ACM Trans Math Softw, 1982, 8: 195-209

84 Zhang Z J, Deng Y F, Teng J W, et al. An overview of the crustal structure of the Tibetan plateau after 35 years of deep seismic soundings. J Asian Earth Sci, 2011, 40: 977-989

85 Tian X B, Wu Q J, Zhang Z J, et al. Joint imaging by telescismic converted and multiple waves and its application in the INDEPTH-III passive seismic array. Geophys Res Lett, 2005, 32: L21315

86 郑洪伟, 孟令顺, 贺日政. 青藏高原布格重力异常匹配滤波分析及其构造意义. 中国地质, 2010, 37: 995-1001

87 Jin S, Ye G F, Wei W B, et al. Electrical structure and fault features of crust and upper mantle beneath the western margin of the Qinghai-Tibet Plateau: Evidence from the magnetotelluric survey along Zhada-Quanshui Lake Profile. J Chin Univer Geosci, 2007, 18: $326-333$

88 Hung S H, Chen W P, Chiao L Y, et al. First multi-scale, finite-frequency tomography illuminates 3-D anatomy of the Tibetan Plateau. Geophys Res Lett, 2010, 37: L06304

89 Zhao J M, Yuan X H, Liu H B, et al. The boundary between the Indian and Asian tectonic plates below Tibet. Proc Natl Acad Sci USA, 2010, 107: 11229-11233

\title{
Deep structure of the central uplift belt in the Qiangtang terrane Tibetan Plateaufrom teleseismic P-wave tomography
}

\author{
ZOU ChangQiao ${ }^{1,2}$, HE RiZheng ${ }^{1}$, GAO Rui ${ }^{1},{\text { ZHANG } \text { Zhi }^{2} \text { \& ZHENG HongWei }}^{1}$ \\ ${ }^{1}$ Institute of Geology Chinese Academy of Geological Sciences, Beijing 100037, China; \\ ${ }^{2}$ College of Earth Sciences, Guilin University of Technology, Guilin 541004, China
}

We have determined a detailed three-dimensional P-wave velocity structure of the crust and upper mantle down to a depth of $200 \mathrm{~km}$ beneath the central uplift belt of Qiangtang by applying Fast Marching Teleseismic Tomography (FMTT) to 9532 high-quality P-wave arrival times. The travel time data were determined by careful interpretations of original seismograms of 506 teleseismic events recorded by a network of 54 broadband stations deployed in the Qiangtang terrane on the Tibetan Plateau during September 2008 and November 2010. Our tomographic imaging beneath the central uplift belt of Qiangtang shows a deep boundary rupture structure for which the lithospheric velocity structure is significantly different on the northern and southern sides. Tomographic images along $33^{\circ} \mathrm{N}$ and $33.5^{\circ} \mathrm{N}$ show that lithospheric structures beneath the sides of the central uplift belt have different scales. The crust at the sides of the central uplift belt exhibits E-W trending high-velocity anomalies. However very low velocities are found within the crust beneath the northern Qiangtang basin overlying and high-velocity anomalies in the lithospheric mantle. Imaging along north-south profiles $\left(88.5^{\circ} \mathrm{E}\right.$ and $\left.89.5^{\circ} \mathrm{E}\right)$ shows that the central uplift of Qiangtang is a significant tectonic boundary fault zone.

central uplift belt of Qiangtang, teleseismic tomography, rupture structure

doi: 10.1360/972011-2430 